\title{
FAILURE MODE AND EFFECT ANALYSIS IN AUTOMOTIVE INDUSTRY: A CASE STUDY
}

\author{
L. PETRESCU, E. CAZACU, MARIA-CĂTĂLINA PETRESCU \\ University POLITEHNICA of Bucharest, Romania, Faculty of Electrical Engineering, \\ 313, Splaiul Independentei, 060042, district 6, Bucharest ROMANIA, \\ E-mail: lucian.petrescu@upb.ro, emil.cazacu@upb.ro, catalina.petrescu@upb.ro
}

\begin{abstract}
Nowadays, Failure Mode and Effect Analysis (FMEA) is more present in any standard evaluation of a product or process. In automotive industry, the IEC 61508 Standard adapted the ISO 26262 restrictions for Electrical and Electronic Devices. Conducting an FMEA reduces the costs by focusing on preventing failures, improving safety and increasing customer satisfaction. This paper presents a case study of a FMEA on a CAN (Controller Area Network) Bus Harness considering the entire process from defining the scope and building the team, to the action plan that will reduce the Risk Priority Number below the acceptable risk value. Also, the brainstorming that identifies the possible failure modes is presented.
\end{abstract}

Keywords: Failure Mode and Effect Analysis, Automotive Standard, CAN Bus Harness

\section{INTRODUCTION}

Failure Mode and Effect Analysis (FMEA) is a systematic flow detection method for identifying and preventing product and process issues. The FMEA focuses on preventing failures, improving safety and increasing customer satisfaction [1, 2]. FMEA describes a series of activities intended to find and estimate the potential failure of a process or product, identify which actions must be taken in order to reduce the potential failure that might occur. The main benefit of a FMEA is to be treated as "before-the-event" procedure and not an "after-the fact" action [1]. FMEA substantially reduces costs if it is used both in the design and manufacturing process.

It can be also used to identify potential improvements that can be brought to the product or process in the conception stage (when changes are relatively easy and inexpensive to achieve) [2].

The FMEA main purpose is to search for all the ways in which a process or a product can fail. A product failure may occur when the product does not work in its normal range [2]. The failures cannot be limited to problems with the product. Some errors may also occur when the user does not use it properly, and these types of malfunctions must be part of an FMEA process. The FMEA must include any action that can ensure the correct functioning of the product / process, no matter how it operates [2].
A FMEA can be extended sometimes to a FMECA (Failure Mode, Effects and Criticality Analysis) process in order to denote that the criticality analysis is performed over the process [3]. A good performed FMEA reduces the time between the appearing the failure mode and its identification. It also reduces the costs for developing counter measuring. From the point of view of the product development phase, there are three types of FMEA: conceptual, design and process.

For all three types of FMEA methods, the same methodology and form is used to document the procedure. The differences are the moment of implementation, the subject of the analysis and the function of the company that has the activities [4]. Accordingly, the conceptual FMEA is the highest level. For this one, it is desirable to detect and prevent failures of systems and subsystems at the most incipient design stages of the project. The FMEA design is a tool for identifying and preventing product failures in their design phase. The FMEA process is used to identify the causes of possible malfunctions that may occur during the devices manufacture or component assembling and to identify the fault elimination measures (Figure 1).

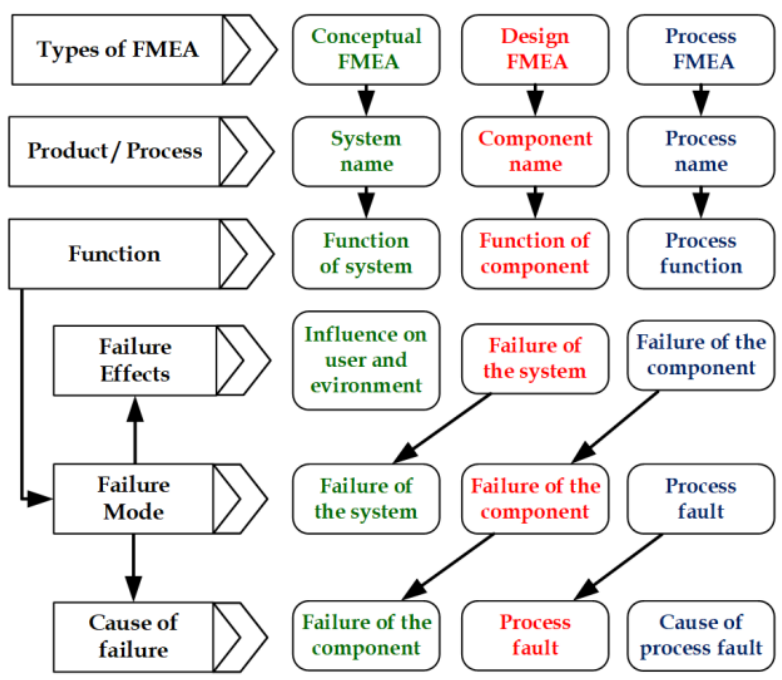

Figure 1. Different connection between the above mention types of FMEAs [3].

Electrical and/or electronic systems have been used for many years to perform safety functions in most application sectors [5]. The use of specific techniques ensures that errors and mistakes are avoided throughout 
their operating lifetime. Errors introduced anywhere from conception, risk analysis, technical specifications, design, installation, maintenance to decommissioning could compromise even the most reliable protection. IEC 61508 specifies the techniques to be used for each phase of product life. This general standard has specific adaptations for different industrial branches: ISO 26262 Functional Safety in Automotive Electronics, EN 50128/EN 50129 in Rail Transportation, IEC 62304 in Medical Service, IEC 670880 in Nuclear Power [6].

ISO 26262 is an International Standard which was published for the first time in 2011 and in 2018 was updated with current new situations involving motorcycles safety, track safety and other important issues [7]. One of ISO 26262 goal is to provide an automotive-specific risk-based approach identified by Automotive Safety Integrity Levels (ASILs). Any FMEA conducted in automotive field must obey this standard.

\section{FMEA METHODOLOGY}

In order to eliminate or mitigate the effects, FMEA manages to select the optimal version to design and develop a documentary base. The latter will support future projects in order to reduce the risks associated with defective systems/products that are used by customers [8].

Conducting any product/design FMEA involves following the next ten steps (Figure 2):

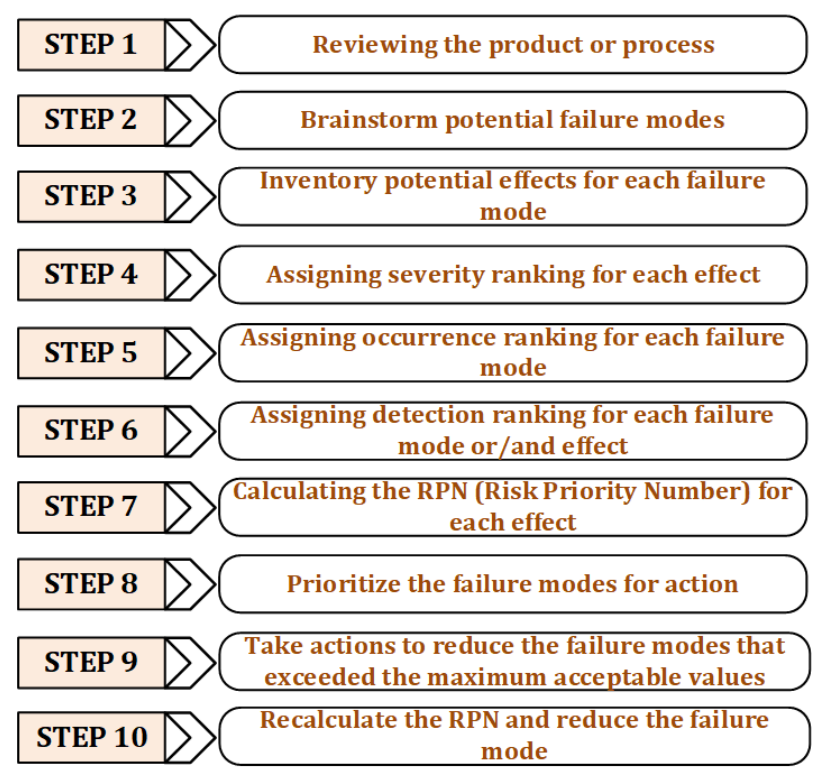

Figure 2. 10 Steps procedures for an FMEA [2].

Although not explicitly stated, a very important initial stage in achieving a successful FMEA is the establishing of a team. FMEA is a dynamic process that does not end with a report put into a drawer at the end. If the team is well organized from the beginning, the necessary iterations are very low. The team must have between 4 and 7 members, from different compartments: production, design, sales, sometimes even from customers, a member can be elected.

The team should review a technical drawing or a blueprint of the product if it considers an FMEA product or a detailed operation diagram if it performs an FMEA process [2]. Once all the team members have understood the process (or product), they can begin to think about possible ways of failure, that could interfere with the manufacturing process or alter product quality (the brainstorming step) $[9,10]$.

The FMEA team analyses every fault mode and determines the potential effects of the malfunction if they occur using the failure modes listed in the FMEA Worksheet. The next stage is to assign ranking from 1 to 10 for the severity $(S)$, occurrence $(O)$ and detection $(D)$. Severity ranking is an estimation of how serious the effects would be if a given failure did occur [2]. The best way to determine the occurrence ranking is to use process data. This may be in the form of process capacity data or even fault logs. When there is no actual fault data, the team must estimate how often a malfunction can occur. The detection ranking indicates how likely we are to detect a failure or the effect of a failure. This step starts from identifying current controls that may detect a failure or a failure effect [2].

At this moment, the FMEA team can calculate the Risk Priority Number (RPN):

$$
\mathrm{RPN}=S \times O \times D
$$

This number alone is irrelevant because for each FMEA can be distinguish a different failure modes and effects. However, it can serve as an indicator to compare the revised total RPN once the recommended actions have been instituted [2].

The failure modes can now be ranked in order, from the highest RPN to the lowest. Each company should choose the maximum acceptable level of the RPN. However, in most of the case this bar is set to 200 (representing $20 \%$ from the top-level of 1000) $[11,12]$. In this point is time for action plan which will try reducing at least one of the severity, occurrence or detection. Once action has been taken to improve the product or process, new rankings for $\mathrm{S}$, O, or/and D should be determined, and a resulting RPN calculated [2].

\section{CASE STUDY - CAN BUS HARNESS}

\subsection{FMEA Preparation}

For all kinds of vehicles, their electrical and electronic equipments should meet IEC 61508 standard requirements [5]. CAN (Controller Area Network) Bus Harness is an essential part of the of a vehicle [13], which defined serial communications bus and was designed to replace the complex wiring harness with a 
two-wire bus [14 - 16] (Figure 3).

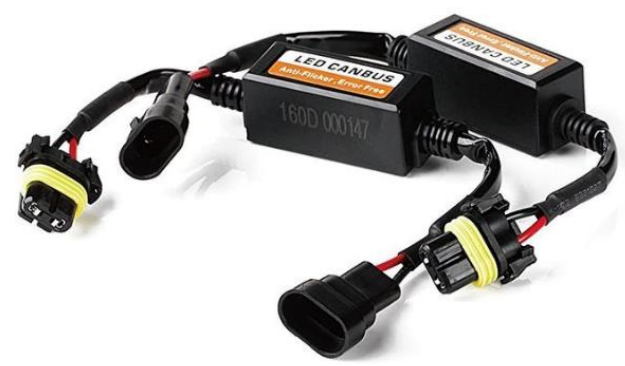

Figure 3. Example of a CAN Bus Harness [14].

First step is to define the Scope of this FMEA. The standard questions for this worksheet can be depicted in Figure 4. In its upper part the product name, the date and the entity who define its scope are to be indicated. First question is "Who is the costumer?". In this case it can be considered any car producer. Then the features and benefits are presented. In the end, is established if the product will be studied entirely or the sub-assemblies are also investigated. The raw materials could also be considered. The packaging is included too and the requirements and constrains are regarded.

\begin{tabular}{|c|}
\hline FMEA Scope Worksheet \\
\hline Product: CAN BUS Harness \\
\hline Date: 07.03 .2019 \\
\hline Scope define by: CAN Bus Harness design group \\
\hline \begin{tabular}{l|l}
1 & Who is the costumer?
\end{tabular} \\
\hline Any car producer \\
\hline \begin{tabular}{l|l}
2 & What are the product features and characteristics?
\end{tabular} \\
\hline $\begin{array}{l}\text { CEM, Speed } 500 \mathrm{~kb} / \mathrm{s}, \text { IPX certified, Temperature resistance } \\
{\left[-40^{\circ} \mathrm{C} /+125 \mathrm{C}\right], \text { chemicals resistance }}\end{array}$ \\
\hline 3 What are the product benefits? \\
\hline $\begin{array}{l}\text { Communication speed } 500 \mathrm{~kb} / \mathrm{s} \text {, IP65 certified, Temperature } \\
{\left[-40^{\circ} \mathrm{C} /+125^{\circ} \mathrm{C}\right]}\end{array}$ \\
\hline \begin{tabular}{|l|l|l|}
4 & Study the entire product or only components or sub-assemblies? \\
\end{tabular} \\
\hline Study of the entire product \\
\hline \begin{tabular}{l|l}
5 & Include considerations of raw material failures? \\
\end{tabular} \\
\hline No \\
\hline \begin{tabular}{l|l|}
6 & Include packaging, storage and transit? \\
\end{tabular} \\
\hline Packaging \\
\hline \begin{tabular}{|r|l|}
7 & What are the manufacturing process requirements and constrains? \\
\end{tabular} \\
\hline Bending factor, Environment storage \\
\hline
\end{tabular}

Figure 4. FMEA Scope Worksheet.

Next, the FMEA Team Start-Up Worksheet must be completed (Figure 5). In the top part the identification number of the FMEA report is presented. Also, the start date and the deadline are reported. Second part contains the component of the FMEA team. For this product, a team of 4 people is selected to be representative of the following departments design, production, car manufacture ad selling, respectively. The suitable team leader is from the design department, the person which is most familiar with the product.

In the middle section of the start-up worksheet the scope is reconfirmed, the team is asked to analyze the competencies and abilities of its members in relation to the scope. It also clarifies whether customers and/or providers are actively involved. In the bottom section of the worksheet, the team must clarify the boundaries of freedom for the project. Start from question 5 to clarify the FMEA status: analyze (and then stop) or issue recommendations (and then stop) or continue to work at FMEA through the implementation phase.

Their help comes with the product blueprint (Figure 6). Other boundaries of freedom include things like limiting financial spending, deadlines and predefined time constraints. The worksheet completes the initial planning stage by establishing the expected communication from the team.

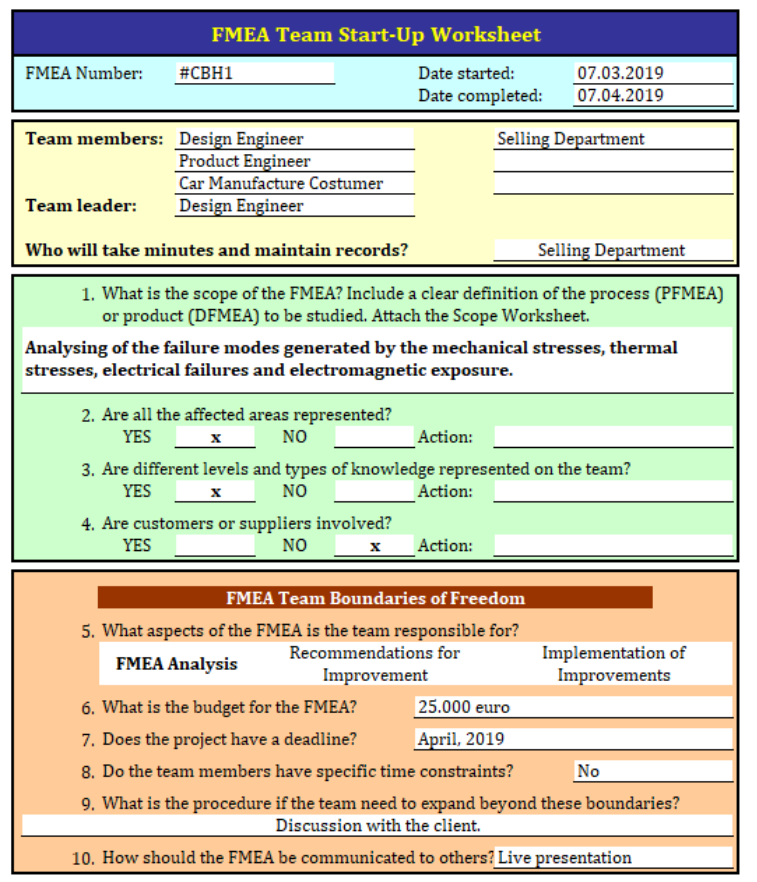

Figure 5. DFMEA Team Sturt-Up Worksheet.

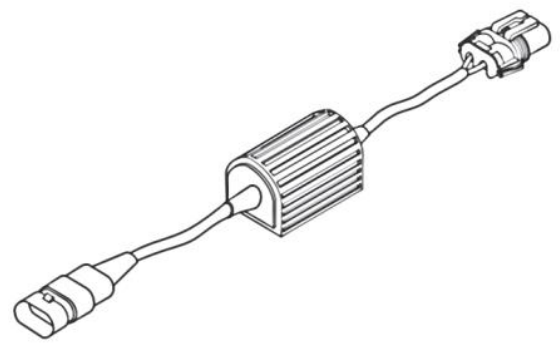

Figure 6. CAN Bus Harness Blueprint [14].

\subsection{FMEA Analysis Worksheet}

In this part of the FMEA the team should consider any manner that the component might fault. Thus, a dynamic list of items, functions and failure modes are defined (Figure 7). At this moment is difficult, but important to distinguish between failure modes, effects and causes. How the product can fail represented the failure mode. The impact of this failure is the effect. And finally, the 
mechanism of the failure is described by the cause of the failure [2].

Identifying the potential effects of failure is the most important aspect in a FMEA. Initially, it must be established if the failure will further influence the costumers, the environment, or even the product itself. It is also essential to fully detail the failure and not to describe it in general terms.

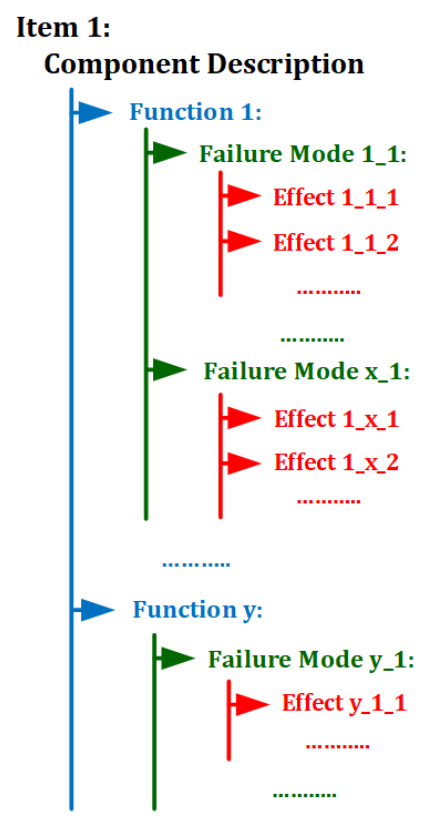

Figure 7. Dynamic list of items, functions, failure modes and effects in a FMEA.

For the CAN Bus Harness considered in this study, Figure 8 depicts the function of the product, the failures modes and the effects identified for each function.

\begin{tabular}{|c|c|c|}
\hline \multicolumn{2}{|c|}{ Failure Mode } & \multirow{2}{*}{ Effect } \\
\hline Function & Failure mode & \\
\hline $\begin{array}{l}\text { Routing sensor data between pieces } \\
\text { of equipment }\end{array}$ & Low resilience to noise & Data coruption \\
\hline \multirow[t]{5}{*}{$\begin{array}{l}\text { Insure the connection between an } \\
\text { equipment and bus }\end{array}$} & $\begin{array}{l}\text { Signal bouncing due to the } \\
\text { vibrations }\end{array}$ & $\begin{array}{l}\text { Transfer data } \\
\text { interruption }\end{array}$ \\
\hline & EM perturbations & $\begin{array}{l}\text { Transfer data } \\
\text { interruption }\end{array}$ \\
\hline & $\begin{array}{l}\text { SCB (short circuit to } \\
\text { battery) }\end{array}$ & Missing data \\
\hline & $\begin{array}{l}\text { SCG (short circuit to } \\
\text { ground) }\end{array}$ & Missing data \\
\hline & OC (open circuit) & Missing data \\
\hline Assembly process & Wrong way connection & $\begin{array}{l}\text { Process time } \\
\text { prolongation due } \\
\text { to return from the } \\
\text { end of assembly } \\
\text { line for repair. }\end{array}$ \\
\hline
\end{tabular}

Figure 8. Functions, failure modes and effect for the CAN Bus Harness FMEA.
Corresponding to these failures modes there, their frequency of appearance was established (Table 1). Also, using a Pareto Diagram [17] (Figure 9) the most frequency failure modes it can be identified. The purpose of a Pareto diagram is to highlight the most important of sets of factors. In FMEA, it is often the most common source of defects, the biggest defect that occurs, or the most common reasons for customer complaints and so on.

Table 1. Failure modes frequency for CAN Bus Harness

\begin{tabular}{|l|c|}
\hline Wrong way connection & 33 \\
\hline Low resilience to noise & 25 \\
\hline EM perturbations & 21 \\
\hline SCB (short circuit to battery) & 12 \\
\hline Signal bouncing due to the vibrations & 10 \\
\hline SCG (short circuit to ground) & 8 \\
\hline OC (open circuit) & 5 \\
\hline Total & 114 \\
\hline
\end{tabular}

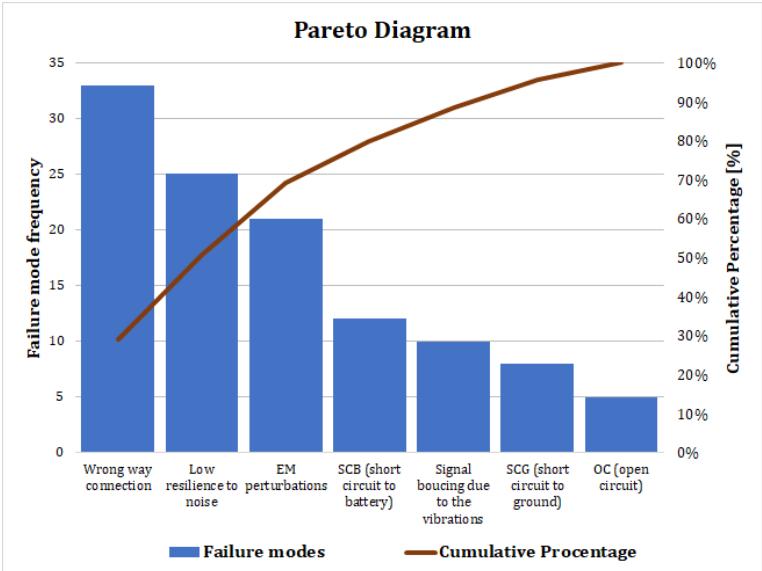

Figure 9. Pareto Diagram for the failure mode studied in current FMEA.

It's the moment now to assign a severity ranking for each failure mode. This is a relative scale from 1 to 10 , where 10 means that the effect could generate to a hazard without warning while 1 means that the severity is extremely low. AIAG (Automotive Industry Action Group) [18] guidelines recommend customizing each scale, to make it easier for each organization. The adaptive severity scale for CAN Bus Harness proposed by the FMEA team can be observed in Figure 10.

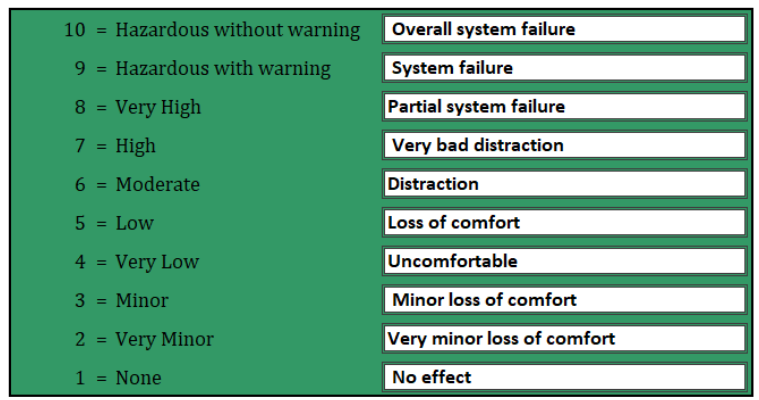

Figure 10. Severity Ranking adaptation for CAN Bus Harness. 
The potential cause of failure technique for each identified failure mode will be further considered. Like the severity ranking, the occurrence ranking scale is a relative scale from 1 to 10 . Here, 10 indicate a very high chance that the failure mode could occur while 1 means that the probability of occurrence is remote. Like the severity, the FMEA team concept an occurrence scale for the CAN Bus Harness (Figure 11).

\begin{tabular}{|c|c|}
\hline $10=$ Very high - Failure happens almost all the time & $\geq 1$ per DC (driving cycle) \\
\hline $9=$ High - Failure occur almost often as not & $\geq 1$ per DC (driving cycle) \\
\hline $8=$ High - Repeated failures & $\geq 1$ per $1000 \mathrm{~km}$ \\
\hline $7=$ High - Failure occur often & $\geq 1$ per $5000 \mathrm{~km}$ \\
\hline $6=$ Moderately high - Frequently failures & $\geq 1$ per $10000 \mathrm{~km}$ \\
\hline $5=$ Moderate - Occasional Failures & $\geq 1$ per $50000 \mathrm{~km}$ \\
\hline $4=$ Moderately Low - Infrequent Failure & $\geq 1$ per $100000 \mathrm{~km}$ \\
\hline 3 = Low - Relatively few failures & $\geq 1$ per $150000 \mathrm{~km}$ \\
\hline $2=$ Low - Failures are few and far between & $\geq 1$ per $200000 \mathrm{~km}$ \\
\hline $1=$ Remote - Failure is unlikely & $<1$ per life cycle \\
\hline
\end{tabular}

Figure 11. Occurrence Ranking adaptation for CAN Bus Harness.

The capability of the design controls to detect or prevent the mechanism of failure represents the detection ranking. Preventive checks prevent the occurrence of the cause or failure mechanism or failure mode. Detection commands detect the cause, fault mechanism or fault mode itself after the malfunction has occurred but before the product is released from the design phase [2]. Like severity and occurrence, the detection ranking is also from 1 to 10 . A detection ranking of 1 means the chance of detecting a failure is almost sure. Instead, a 10 means the detection of a failure or mechanism of failure is completely uncertain.

The adaptation of this scale for the CAN Bus Harness FMEA is presented in Figure 12.

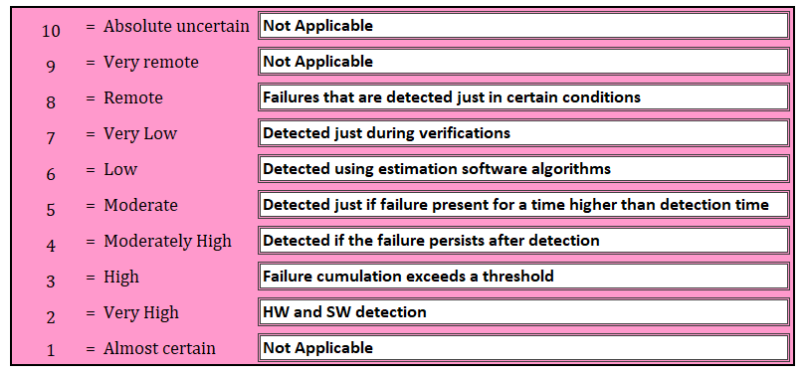

Figure 12. Detection Ranking adaptation for CAN Bus Harness.

Figure 13 is shows the resulting FMEA process that will generate the RPN using (1). The RPN is calculated by multiplying the three rankings together. For this reason, PRN is from 1 to 1000 . The RPN gives the FMEA team an excellent tool to prioritize focused improvement efforts.

In most situations, an organization considers an acceptable risk for which RPS has a value below 200 (i.e. $20 \%$ of the maximum). In the case of this FMEA, one can notice that two of the failure modes excided this value so the Action Plan that is following the FMEA will be focused on these only.

First, failure mode defines as signal bouncing due to the vibration has a high value of the severity (9). The FMEA team considers using protective coats that maintain their properties (mechanical and chemical) at extreme temperatures, fireproof material. Also, the design engineering proposes developing of a SWC (software component) for failure detection and software reconfiguration. After implementing these actions, the results might improve resistance to extreme temperatures and fireproofing. As well, the failure detection improved, and the effect is reduced. In the end, the severity is

\begin{tabular}{|c|c|c|c|c|c|c|c|c|c|}
\hline \multicolumn{10}{|c|}{$1+2$} \\
\hline \multicolumn{10}{|c|}{ FMEA Process } \\
\hline \multicolumn{2}{|c|}{ Failure Mode } & \multirow{2}{*}{ Effect } & \multirow{2}{*}{$\mathrm{s}$} & \multirow{2}{*}{ Cause } & \multirow{2}{*}{$0-$} & \multicolumn{2}{|c|}{ Controls } & \multirow[b]{2}{*}{ D } & \multirow{2}{*}{ RPN } \\
\hline Function & Failure mode & & & & & Prevention & Detection & & \\
\hline $\begin{array}{l}\text { Routing sensor data between } \\
\text { pieces of equipment }\end{array}$ & Low resilience to noise & Data coruption & 6 & Designing mistake & 3 & $\begin{array}{l}\text { Detection during verifications at } \\
\text { the EOP (end of production line). }\end{array}$ & $\begin{array}{l}\text { In case of non-detection at end } \\
\text { of production line the failure is } \\
\text { detected at the end of } \\
\text { assembly line systems testing. }\end{array}$ & 3 & 54 \\
\hline \multirow[t]{5}{*}{$\begin{array}{l}\text { Insure the connection between an } \\
\text { equipment and bus }\end{array}$} & $\begin{array}{l}\text { Signal bouncing due to } \\
\text { the vibrations }\end{array}$ & $\begin{array}{l}\text { Transfer data } \\
\text { interruption }\end{array}$ & 9 & $\begin{array}{l}\text { Material degradation in time } \\
\text { caused by temperature } \\
\text { (positive and negative) }\end{array}$ & $6 \mid \mathrm{s}$ & No & $\begin{array}{l}\text { Software detects } \\
\text { communication loss }\end{array}$ & 6 & 324 \\
\hline & EM perturbations & $\begin{array}{l}\text { Transfer data } \\
\text { interruption }\end{array}$ & 8 & $\begin{array}{l}\text { Instalation near EM sources } \\
\text { (alternator, starter) }\end{array}$ & & $\begin{array}{l}\text { The system can prepare before } \\
\text { starting the high current } \\
\text { consumers }\end{array}$ & $\begin{array}{l}\text { Software detects erroneous } \\
\text { frames with a high } \\
\text { probability, illegal data not } \\
\text { processed }\end{array}$ & 8 & 128 \\
\hline & $\begin{array}{l}\text { SCB (short circuit to } \\
\text { battery) }\end{array}$ & Missing data & 9 & $\begin{array}{l}\text { Wrong way connection, } \\
\text { (human factor) } \\
\text { The bending radius inside } \\
\text { anssembling not respected }\end{array}$ & 31 & No & $\begin{array}{l}\text { Software detects } \\
\text { communication loss }\end{array}$ & 2 & 54 \\
\hline & $\begin{array}{l}\text { SCG (short circuit to } \\
\text { ground) }\end{array}$ & Missing data & 9 & $\begin{array}{l}\text { Wrong way connection, } \\
\text { (human factor) } \\
\text { The bending radius inside } \\
\text { anssembling not respected }\end{array}$ & 2 & No & $\begin{array}{l}\text { Software detects } \\
\text { communication loss }\end{array}$ & 2 & 36 \\
\hline & OC (open circuit) & Missing data & 9 & $\begin{array}{l}\text { Wrong way connection, } \\
\text { (human factor) } \\
\text { The bending radius inside } \\
\text { anssembling not respected } \\
\end{array}$ & 2 & No & $\begin{array}{l}\text { Software detects } \\
\text { communication loss }\end{array}$ & 2 & 36 \\
\hline Assembly process & Wrong way connection & \begin{tabular}{|l|} 
Process time \\
prolongation due \\
to return from the \\
end of assembly \\
line for repair.
\end{tabular} & 6 & Human factor & & No & $\begin{array}{l}\text { Detection at the end of } \\
\text { assembly line systems testing }\end{array}$ & 7 & 252 \\
\hline
\end{tabular}

Figure 13. FMEA Process resulting RPN's after assigning severity, occurrence and detection values. 
reduced to 5 and with this the RPN becomes:

$$
\mathrm{RPN}=5 \times 6 \times 6=180
$$

The second failure mode is caused by a wrong connection of the CAN Bus Harness. For this one the prevention is absent because of the human factor which will be detected only in the assembly line system testing. By implementing one-way connection plug, the detection decreases to 4 . The recalculated RPN is now:

$$
\mathrm{RPN}=6 \times 6 \times 4=144
$$

This concludes the Action Plan and Results diminishes all RPN's below 200.

\section{CONCLUSIONS}

The aim of this paper is to present the entire process of developing a FMEA in Automotive Industry. This kind of FMEA must obey the IEC Standard 61508 for Electrical and Electronic Devices in Automotive. The product chosen for conducting the FMEA is the CAN Bus Harness which equips all cars and becomes an essential part of the vehicle safety operation.

The FMEA begins with defining its scope. This will focus on studying the entire product, considering also the packaging. The FMEA Start-Up Team involves specialists from design, production, selling and manufacturer. It has a time span of a month and the budget is established to be 25.000 euro.

FMEA team brainstorms and found 7 possible failure modes for the CAN Bus Harness (Figure 8). A frequency analysis indicates that the wrong way connection and the low resilience to noise are most common failure modes. Furthermore, according to the AIAG recommendation, the FMEA team develops particular ranking scales for severity, occurrence and detection. Assigning each failure mode, the severity, occurrence and detection were considered by the FMEA team and the full FMEA process is completed and each failure mode has an RPN. In the end, two of the failure modes had an RPN that exceeds the acceptable value of 200. By reducing the severity from 9 to 5 for the signal bouncing due to the vibration and the detection from 7 to 4 for wrong connection of the CAN Bus Harness, both failure modes are reduced to 180 . This way the FMEA achieves its goal.

\section{REFERENCES}

[1] Failure Mode and Effect Analysis, FMEA Handbook (with Robustness Linkages), FMEA Handbook Version 4.2, December 2011.

[2] R.E., McDermott, R.J., Mikulak, M.B., Beauregard, The Basics of FMEA, 2nd Edition, 2009, CRC Press.

[3] https://quality-one.com/fmea/.
[4] D. Catic, S. Arsovski, B. Jeremic, J. Glisovic, FMEA in product development phase, 5th International Quality Conference, May 20th 201, p. 679-686.

[5] IEC 61508 Standard, https://www.iec.ch/.

[6] An introduction to Functional Safety and IEC 61508, Application Note, Eaton.

[7] B.J. Czerny, J. D'Ambrosio, R. Debouk, ISO 26262 Functional Safety Draft International Standard for Road Vehicles: Background, Status, and Overview, General Motors Research and Development.

[8] S. Rana, R.M. Belokar, Quality Improvement Using FMEA: A Short Review, International Research Journal of Engineering and Technology (IRJET), Vol. 4, Iss. 6, June 2017, p. $263-267$.

[9] N. Belu, N. Rachieru, E. Militaru, D.C. Anghel, Application of FMEA Method in Product Development Stage, Academic Journal of Manufacturing Engineering, 10 (3), March 2012, p. 12 -19 .

[10] D. Juhaszova, Failure Analysis in Development \& Manufacture for Customer, Quality Innovation Prosperity, XVII/2 - 2013, p. 89 - 102, DOI: 10.12776/QIP.V17I2.203.

[11] T.S. Parsana, M.T. Patel, A Case Study: A Process FMEA Tool to Enhance Quality and Efficiency of Manufacturing Industry, Bonfring International Journal of Industrial Engineering and Management Science, Vol. 4, No. 3, August 2014, p. 145 - 152, DOI: 10.9.

[12] I. Lingvay, A.M. Borş, D. Lingvay, C.M. Bălăceanu, Automobilul electric: mit şi realitate privind poluarea mediului" (Electric vehicle: Myth and Reality concerning the Environment Pollution), Electrotehnica, Electronica, Automatica (EEA), 2017, vol. 65 , no. 4, pp. 5-11, ISSN 1582-5175.

[13] C.S. Carlson, Effective FMEAs: Achieving Safe, Reliable, and Economical Products and Processes using Failure Mode and Effects Analysis, John Wiley \& Sons, Wiley Series in Quality \& Reliability Engineering, 2012.

[14] Introduction to the Controller Area Network (CAN), Application report, Texas Instruments, May 2016.

[15] T.M. Băjenescu, Nitrura de galiu (GaN) carbura de siliciu (SiC) și automobilul de mâine”, (Gallium Nitride (GaN) Silicon Carbide ( $\mathrm{SiC}$ ) and the Future Vehicle), in Electrotehnica, Electronica, Automatica (EEA), 2017, vol. 65 (1), pp. 54-61, ISSN 1582-5175.

[16] H. Mansor, K. Markantonakis, K. Mayes, CAN Bus Risk Analysis Revisit, 8th IFIP International Workshop on Information Security Theory and Practice (WISTP), Jun 2014, Heraklion, Crete, Greece, p. 1-11.

[17] A. Ora, D. Kumar, N. Darade, Failure Mode Effect Analysis with Pareto Chart for Various Critical Equipment used in Ceramic Industry, International Journal of Engineering Science and Computing, April 2017, vol. 7, iss. 4, p. 10168-10173.

[18] https://www.aiag.org/ 